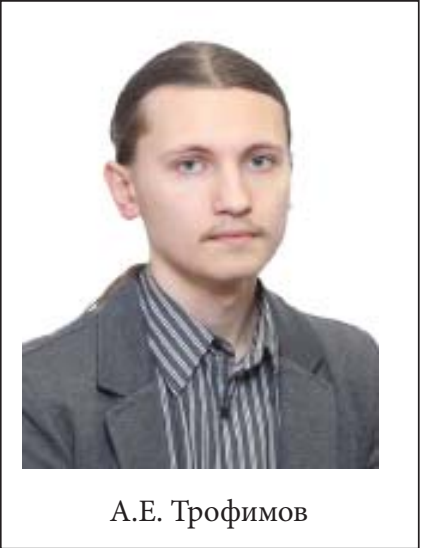

\title{
ОПЫТ КОМПЛЕКСНОГО ЛИНГВИСТИЧЕСКОГО АНАЛИЗА СТИХОТВОРЕНИЯ А.П. СУМАРОКОВА «ИЗ 145 ПСАЛМА»(1773)
}

\author{
A.E. Трофимов ${ }^{*}$
}

Аннотация: В статье дается всестороннее лингвистическое рассмотрение стихотворения А.П. Сумарокова «Из 145 псалма»; выявляются жанровая специфика текста, особенности его стиля, фоники, метрики, строфики, лексики, композиции, степень его соответствия классицистическим канонам и элементы поэтического новаторства.

Ключевые слова: А.П. Сумароков, классицизм, псалом, строфра, стих, стиль, язык, перевод.

Религиозная поэзия Александра Петровича Сумарокова (1717-1777 гг.), и в частности перевод на русский язык Псалтыри (работа осуществлялась с 1743 до конца 1770-х гг.), занимает особое место не только в творчестве этого автора, но и в общем контексте отечественной словесности риторической эпохи. Г.А. Гуковский так охарактеризовал перевод Сумароковым из Библии: «Его псалмы - это лирические песни о человеке, изнемогающем под бременем жизни и ненавидящем порок» [2, с. 151]. Н.А. Гуськов отмечает, что перевод Псалтыри был выполнен поэтом на склоне лет и воплощает в себе все наиболее яркие стороны его литературного дарования [3, с. 33-34].

Псалом является одним из древнейших жанров мировой лирики. 151 стихотворение - собрание песен, «излагающих благочестивые излияния восторженного сердца при разных испытаниях жизни» [4, с. 1933], - в совокупности входит в Псалтырь (Псалтирь), одну из священных книг Ветхого Завета. Традиционный псалом представляет собой восторженный монолог лирического героя, обращенный к Богу с хвалой и благодарностью. С.С. Аверинцев отмечает, что отличительной чертой псалма на фоне других жанров древней ближневосточной лирики является резко личностный характер [1, с. 372]. В XVIII веке к переводу Псалтыри, помимо А.П. Сумарокова, обращались Феофран Прокопович, А.Д. Кантемир, В.К. Тредиаковский, М.В. Ломоносов и др. При этом именно у Сумарокова, одного из наиболее последовательных классицистов, литературоведами и критиками неоднократно отмечались отклонения от традиционного жанрового канона и включение в религиозный жанр как интимного, личностного переживания, так и общей морально-этической, а не религиозной составляющей: «Если лирический герой Сумарокова напоминал библейского псалмопевца, то повествователь в переложениях псалмов обрел и отдельные сумароковские черты», - отмечает Н.А. Гуськов [3, с. 34]; «Сумароков приглушил основной тон псалма, зато усилил общеморальную тенденцию», - комментирует методологию поэта на материале текста «Из 145 псалма» (о котором и пойдет у нас речь) П.Н. Берков [5, с. 524].

Приступая к работе, нам стоит упомянуть, что при переводе псалма Сумароков ориентировался на читателя, знакомого с оригиналом. Этот факт позволяет говорить о наличии претекста для данного стихотворения, что оказывает существенное влияние на его анализ. Поэтому мы считаем нужным привести, помимо стихотворения А.П. Сумарокова, церковнославянский оригинал псалма 145, на который, что совершенно очевидно, ориентировался поэт (жирным шрифтом выделен фррагмент, почти дословно цитируемый Сумароковым в переводе):

1 Не уповайте на князей:

2 Они рожденны от людей,

3 И всяк по естеству на свете честью равен.

4 Земля родит, земля пожрет;

5 Рожденный всяк, рожден умрет,

6 Богат и нищ, презрен и славен.

7 Тогда исчезнут лести те,

8 Которы данны суете

9 И чем гордилися бесстыдно человеки;

10 Скончаются их кратки дни,

11 И вечно протекут они,

12 Как гордые, шумя, текущи быстро реки.

13 Когда из них изыдет дух,

14 О них пребудет только слух,

15 Лежащих у земли бесчувственно в утробе;

16 Лишатся гордостей своих,

17 Погибнут помышленья их,

18 И пышны титла все сокроются во гробе [6, с. 28].

«Хвали доуше моА Гда: Восхвалю Гда въ животь моемъ, пою Бгоу моемоу дондеже есмь. Не надъйтес囚 на кн囚зи, на сыны члвъческі囚, въ нихже нъсть спасені囚: Изыдетъ доухъ ег囚 и возвратитс区 въ землю свою: в той день погибноуть вс区 помышлені叉 ег囚. Блженъ, емоуже Бгъ Іакшвль помощникъ егш, 
оупованїе егш на Гда Бга своего: Сотворшаго нбо и землю, море, и всА, же въ нихъ: хранАщаго истиноу въ вькъ: ТворАщаго соудъ шбидимымъ: дающаго пищоу алчоущымъ. Гдь рьшитъ шкованныА: Гдь оумоудрАетъ сльпцы: Гдь возводитъ низверженныА: Гдь любитъ праведники: Гдь хранитъ пришлецы, сира и вдовоу прїиметъ: и поуть грьшныхъ погоубитъ ВоцритсА Гдь во вькъ, Бгъ твой Сїшне в родъ и родъ» [7, с. 229].

Как можно заметить по стихам 1, 2, 3, 13, 15, 17, дословно переведено чуть менее половины выделенного фрагмента. Л.Ф. Луцевич справедливо замечает, что Сумароков фриксирует в них не только религиозную догму, но и популярный в среде русских просветителей XVIII века тезис о природном равенстве всех людей [8, с. 349]. Большую же часть псалма, в которой содержится восхваление Бога и Его величия, автор переложения опускает. Анализ покажет, к каким средствам прибегает поэт для выполнения своей художественной задачи (опосредованно констатируемой уже из наблюдений виднейших специалистов).

Уже при первом прочтении бросается в глаза одна из основных черт сумароковского стиля отсутствие ярких образов. В отличие, например, от большинства стихотворений М.В. Ломоносова, изобилующих барочной образностью и метафорикой, здесь находит воплощение традиционный для поэта «сухой» стиль. На лексическом уровне обилие отвлеченных понятий: «лесть», «естество», «суета», «дух», «гордость», «помышление» и др. не создает в глазах читателя эффректной «картинки», но, напротив, позволяет обратиться к вечным философским проблемам бытия и абстрактным сущностям. Следует заметить, что почти ни один глагол в данном тексте не употреблен в настоящем времени, что также «размывает» складывающийся образ. Подкрепляется это общей темой стихотворения - вечными законами жизни и смерти, которым подвластны все люди, вне зависимости от происхождения и социального статуса.

По своему семантическому и синтаксическому наполнению резко выделяется первая строфра. Первые два стиха являются почти буквальным переводом церковнославянского текста, третий же («И всяк по естеству на свете честью равен») выбивается как семантически (смысл, который вносит сам поэт), так и визуально (стих длиннее и содержит большее количество стоп), придавая тем самым дополнительный эффрект заложенной в нем мысли. Сам по себе он (хотя и соединен союзом «и» с предшествующими) выделяется как бы особой афористичностью, в нем словно заключается неоспоримый закон бытия. Неожиданным кажется и заключенный в нем смысл: в духовном жанре неожиданно возникает тема естества и природного равенства людей. Как справедливо замечает Л.Ф. Луцевич, это наталкивает на мысль о том, что собственная мысль Сумарокова воплощалась в его духовной поэзии в исключительно светском ключе, в частности - в направлении господствовавшего в XVIII веке Просвещения, а не в русле духовного жанра [8, с. 325-326].

Следующая часть строфы (стихи 4-6) отличается явной симметричностью двух частей одного стиха и синтаксическим параллелизмом: «земля родит, земля пожрет» - чередование подлежащего (причем одного и того же, вплоть до лексического повтора) и сказуемого. «Рожденный всяк, рожден умрет» - несколько более сложная ситуация: полная и краткая формы причастия также играют роли семантически одного подлежащего; «всяк» и «умрет» выступают в роли сказуемых, но не столь явных, как глаголы в предыдущем стихе, поэтому синтаксическая структура здесь в определенной мере скрыта. «Богат и нищ, презрен и славен» перечисление однородных членов (прилагательных), образец синтаксического параллелизма.

Итак, можно сказать, что вторая часть данной строфы своими повторами и монотонностью создает эфффект цикличности времени, побороть которое не властны и сильные мира сего. Эта мысль явно акцентируется автором стихотворения и выделяется при помощи обозначенного выше нарушения ожидания с неравномерной сменой размера в стихах. Позволяет соотнести стих 6 со стихом 3 и его графическое офрормление: в издании стихотворений Сумарокова 1935 г. напечатан он также с уклоном несколько левее. Подробнее функция такого оформления будет рассмотрена ниже.

Неповторимый «библейский» стиль создают и особенности морфологии. Так, употребленная в данном тексте форма множественного числа именительного падежа от слова «человек» - «человеки», вместо «люди» - характерна для традиционного языка славянской Библии; достаточно вспомнить такие распространенные в священной книге выражения, как «Ловец Человеков» (Мф. 4:19; Мк. 1:17 и др.), «Страж Человеков» (Иов. 7:20.), «Спаситель всех Человеков» (1 Тим. 4:10) и т. п. Необходимо отметить также один из редких в данном тексте тропов - сравнение «Как гордые, шумя, текущи быстро реки». Река - также библейский образ, довольно часто встречающийся на страницах священной книги и традиционно олицетворяющий жизнь вечную (см., например: Еккл. 1:7; Ин. 7:38; Откр. 16:4 и др.). Откуда конкретно взял этот образ Сумароков - сказать затруднительно, для этого требуется более тщательное и специальное исследование. Если учесть устоявшуюся семантику данного образа, то любопытным покажется его взаимодействие с основной темой данного стихотворения, когда с традиционным образом вечной жизни сравнивается вечная смерть: "Скончаются их кратки дни, // И вечно протекут они, // Как гордые, шумя, текущи быстро реки». Возможно, это подкрепляет тезис о нескончаемом чередовании жизни и смерти, цикличности человеческого бытия, которое пытается изобразить поэт.

Звуковой уровень, или фонику данного стихот- 
ворения демонстрирует следующая вокалическая решетка (рис.1)

Нетрудно заметить, что на вокалической решетке отражены все шесть гласных звуков русского языка. Видно, что звучание клаузул делит стихотворение на две не вполне симметричные части: 1-12 и 13-18 стихи. В клаузулах первой из двух частей абсолютно преобладает звук /э/ (ударный в 18 случаях), а также отчасти /a/ (11) и /и/ (5). При сопоставлении с представленным выше текстом самого псалма становится очевидным, что звук /э/ почти дословно, на уровне цитирования, отсылает к основным смыслообразующим словам претекста: (не) надъйтесА, (сыны) члвъчческї̈, нгссть, спасенїА, а также день, помышленїА. Таким образом, звук /э/ приобретает семантику трагичности и безысходности, которая поддерживается на всем протяжении строфр 1 и 2. Можно увидеть, как этим звуком обозначаются наиболее существенные мотивы: тщетная человеческая надежда и отсутствие всякого спасения от рока судьбы. Интересно, что в строфе 2 этот же звук присутствует также в ключевых словофрормах: «лести», «суете», «реки», «человеки» - то есть развертывание псалтырной темы тщетности надежды и отсутствия спасения у человека напрямую сопоставляются автором с основными, на его взгляд, пороками человека: лестью и суетой. Забегая несколько вперед, обратим внимание на то, что выделяются данные слова и интонационно: в двух стихах подряд - 8 и 9 - пропуск ударения на третьей стопе ставит в позицию восходящей интонации слово «суете» (а в стихе 8 - еще и мужской словораздел), что подчеркивает его и выделяет как источник человеческих бед. Вообще же в духовных стихотворениях Сумарокову присуще органичное связывание светского порока с пороком духовным, что справедливо замечает Л.Ф. Луцевич [8, с. 328-329]. Необходимо также обратить внимание на то, что поэт повторно обращается к звуку /э/ в последних двух стихах (словоформы «помышления», «все»); объяснение этому будет дано ниже.

В последней строфе звуковое оформление резко меняется: «Когда из них изыдет дух, // О них пребудет только слух, // Лежащих у земли бесчувственно в утробе; // Лишатся гордостей своих, // Погибнут помышленья их, // И пышны титла все сокроются во гробе». Преобладать, как можно заметить, начинают артикуляторно близкие друг другу лабиализованные звуки /y/ и /о/, которые, в соответствии с содержанием, создают ощущение могильного холода, мрачного загробного мира. Дополнительную «зловещесть» придает этой строфе и нисходящая интонация в словах "бесчувственно» (стих 15) и «сокроются» (стих 18), создаваемая при помощи дактилического словораздела в обоих случаях. Также фрункцию дополнительной инструментовки несут регулярный повтор глухого звука

\begin{tabular}{|c|c|c|c|c|c|c|}
\hline & I & II & III & IV & $\mathrm{V}$ & VI \\
\hline & & $\mathrm{a}$ & & $\ni$ & & \\
\hline & & 3 & & $\ni$ & & \\
\hline & $\mathrm{a}$ & & $\mathrm{y}$ & $\ni$ & 3 & A \\
\hline & a & и & a & $\ni$ & & \\
\hline & 3 & $\mathrm{a}$ & 3 & $\ni$ & & \\
\hline & a & и & 3 & A & & \\
\hline & a & 3 & 3 & $\ni$ & & \\
\hline & 0 & a & & $\ni$ & & \\
\hline & 3 & и & & Ы & & $\ni$ \\
\hline 10 & a & & a & И & & \\
\hline 11 & 3 & & $y$ & И & & \\
\hline 12 & $\begin{array}{l}0 \\
a\end{array}$ & и & $\begin{array}{l}\text { a } \\
\text { ы }\end{array}$ & $\begin{array}{l}\mathrm{y} \\
\mathrm{y}\end{array}$ & ы & $\ni$ \\
\hline 14 & и & $y$ & 0 & $\mathrm{y}$ & & \\
\hline 15 & a & & и & $\mathrm{y}$ & & 0 \\
\hline 16 & a & 0 & & И & & \\
\hline 17 & и & & 3 & И & & \\
\hline 8 & ы & и & 3 & $\mathrm{O}$ & & 0 \\
\hline
\end{tabular}

Puc. 1

/X/, который можно соотнести с дуновением ветра, ощущением пустоты и безжизненности, и повтор шипящих /ш/, /щ/, /ж/, тоже придающий строфе дополнительную организованность и напоминающий собой словно шепот из загробного мира. С точки зрения образности эта часть стихотворения как раз кажется наиболее яркой и, как ни парадоксально, материально «живой» и зримой: здесь происходит не просто упоминание смерти, как было в предыдущих строфах, а едва ли не физическое ее изображение.

Обращает на себя внимание также созвучие некоторых согласных фонем и особенности их сочетания. Так, в словах «пожрет» и «рожден» выделенные фронемы /p/ и /ж/, меняя позицию по отношению друг к другу и согласуясь с семантикой слов, демонстрируют будто циклическое чередование жизни и смерти: /рж/ - рождение, /жр/ - наоборот - смерть. Использую типологию, предложенную О. М. Бриком, можно отнести такую смену позиций двух согласных к типу АВ-ВА [9, с. 69]. Учитывая, что такое сочетание фонем в стихах 4 и 5 встречается в конце и начале строчек, можно назвать этот случай, прибегая к терминологии Брика, «стыком» («основа в конце строки, повтор в начале следующей») [9, с. 83]. Интересно, что атмосфрера цикличности вообще присуща поэтической манере Сумарокова в его духовной лирике, что отмечает Л.Ф. Луцевич [8, с. 338].

В плане слогового строения (метрики) в данном стихотворении представлены 6 мужских (нулевых) клаузул и 3 женских (односложных). Приходим к выводам, что, на основании данного стихотворения, новатором в области рифмы Сумарокова назвать трудно: абсолютное большинство рифм с 
Табл. 1

\begin{tabular}{|l|l|l|l|l|l|l|l|l|l|l|l|l|l|}
\hline Стих & 1 & 2 & 4 & 5 & 6 & 7 & 8 & 10 & 11 & 13 & 14 & 16 & 17 \\
\hline Пропуск & I, III & I, III & - & - & - & - & III & II & II & - & - & III & II \\
\hline
\end{tabular}

Табл. 2

\begin{tabular}{|l|l|ll|l|l|}
\hline Стих & 3 & 9 & 12 & 15 & 18 \\
\hline Пропуск & II & III, V & II & II, V & V \\
\hline
\end{tabular}

фонетической точки зрения являются точными и бедными, однородными и грамматическими, что в целом характерно для поэзии русского классицизма середины и второй половины XVIII в. Кроме того, в соответствии с поэтическими тенденциями эпохи, Сумароковым соблюдается правило альтернанса.

Также на «традиционность» Сумарокова указывают метр и размер стиха. Данный текст написан в тонической системе стихосложения (в ее силлаботонической подсистеме, так как объем междуиктового интервала здесь фриксирован) и целиком выдержан ямбом (по данным, которые приводит К.Д. Вишневский, около 80 \% всех поэтических текстов XVIII в. на русском языке) [10, с. 129-231]; размер его, однако, колеблется от четырех (Я4) до шести (Я6) стоп. (Ранее было сказано, в каких случаях и с какой целью происходит «удлинение» стихотворной строки). Таким образом, размер данного стихотворения определяется как классический двустопный с односложной анакрузой, но число сильных мест в стихах колеблется (от 4 до 6), иначе говоря - разностопный ямб (ЯРз). В совокупности с Я4 и Я6 (оба из которых представлены в данном тексте) такой размер встречается более чем в 70 \% поэтических произведений эпохи. Судя по всему, в данном случае ЯРз придает стихотворению имитацию разговорной речи, что подкрепляет высказанный ранее тезис о светском, разговорном, «естественном» языке сумароковских переложений псалмов [3, с. 34]. Поэтому использование данного размера в духовном жанре нетипично и тоже выглядит смелым новаторством, хотя встречается у избранного автора довольно часто.

Обращает на себя внимание выбор именно этого вида стихотворного метра. Семантика ямба так объясняется самим поэтом: ямб «разговору ${ }^{1}$ посвящен, и больше епической поеме, трагедии, комедии и сатире принадлежит» [6, с. 391]. В этом плане выбор Сумарокова, очевидно, обуславливается не только стремлением придать священному церковному жанру более живой, разговорный оттенок, но и приблизить его к жанрам «светским», как поэма или драматические произведения. Впрочем, стоит отметить, что большинство стихотворных переложений псалмов, выполненных Сумароковым, также написаны ямбом, причем нередко разностопным.

Грамматический характер рифмопар в разных строфрах (CС - ПП - ГГ; МС - CС - CM; CC - CC ММ) также позволяет сделать некоторые наблюдения. Как видно, первая и третья строфы имеют исключительно грамматически однородные рифмы, однако во второй строфе существительные начинают рифрмоваться с местоимениями, что позволяет выделить ее на фроне остальных.

Ритмическая форма стихотворения выглядит следующим образом:

$$
\begin{aligned}
& U-U-\cdot U \mid-U-\cdot \\
& U-U-\cdot U \mid-U-'
\end{aligned}
$$

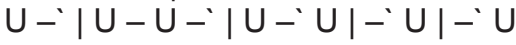

$$
\begin{aligned}
& U-'|U-'| U-'|U-`|
\end{aligned}
$$

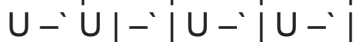

$$
\begin{aligned}
& \text { U-'|U-'|U-'|U-'U } \\
& U-`|U-` U|-' U \mid-` \\
& U-\cdot U|-' U|-U-' \\
& U-'|U-' U-| U-' U \mid-U-' U \\
& U-' U-|U-' U|-' \\
& U-' U|-U-'| U-' \\
& U-' U-|U-'| U--^{\prime} U|-' U|-' U \\
& \text { U-`|U-`|U-`U|-` } \\
& U-`|U-\cdot U|-\cdot U \mid-\cdot \\
& U-' U|-U-'| U-' U-\mid U-' U \\
& U-' U|-' U-| U-' \\
& U-' U|-U-' U|-` \\
& U-^{\prime} U|-' U-| U-' U-\mid U-' U
\end{aligned}
$$

Как можно заметить, на протяжении всего стихотворения нередко встречаются пропуски метрических ударений (пиррихии). Можно охарактеризовать стихи 1-17 следующим образом (первая строчка таблицы - номер стиха, вторая - позиция пропуска ударения) (табл. 1).

Оставшиеся стихи с Я6 (номера 3-18) охарактеризуем следующим образом (табл. 2).

Сверхсхемные ударения в данном тексте отсутствуют.

Представленная схема позволяет рассмотреть некоторые особенности текста. Во-первых, пиррихии в стихах 1 и 2 строфы 1 расположены практически симметрично по отношению друг к другу, в них равномерно чередуются женский словораздел с мужской клаузулой в конце стиха - этот ритми-

${ }^{1}$ Cтоит отметить, что в XVIII в. под «разговором» понимались не только «беседа, разглагольствие, взаимное с кем рассуждение о чем», но и «род сочинения, в котором содержатся разглагольствия между двумя или многими лицами», то есть драматические произведения, а также произведения, содержащие диалог между героями [11, с. 155-156]. 
ческий повтор дает основание для выделения данных стихов на фоне остальных: в них содержится выдвижение тезиса и его аргументация, дающие посыл всему стихотворению. Во-вторых, можно заметить, что в стихе 3 строфы 1 мужской словораздел в первом полустишии вдруг резко сменяется женским, что также, помимо визуальной длины, выделяет стих на фоне двух предыдущих. В-третьих, можно заметить, что упорядоченный словораздел присутствует почти во всех стихах первой и третьей строф, но отсутствует во второй, то есть на уровне словораздела по принципу гармоничной упорядоченности почти во всех стихах первой и третьей строф наблюдается связь, в отличие от неупорядоченной в этом плане второй строфы; возможно, объяснение этому можно найти, взглянув на оригинал переводного псалма: в первой и третьей строфах Сумароков преимущественно старается следовать оригиналу, тогда как вторая строфра - целиком привнесение самого поэта; возможно, отсутствие связи с другими строфрами вносит в строфу 2 более разговорный речевой оттенок. Тем не менее, нельзя сказать, что она целиком асимметрична: дополнительную упорядоченность и организованность придают ей пропуски метрического ударения на одинаковых позициях - на 3-й стопе - в стихах 8 и 9, а также пропуски на других позициях в стихах 10, 11 и 12 - на 2-й стопе. В стихах, написанных Я6 (3, 9, 12, 15, 18), находится цезура, регулярно встречающаяся в данном размере.

Характерен строфический уровень стихотворения. Видно, что строфы в данном тексте графрически разделены; рифмовка стихотворения выглядит следующим образом: aаВсcВ. Данный тип для эпохи Сумарокова является довольно широко употребляемым, хотя получил преимущественное распространение позже - у романтиков и неоромантиков, с которыми связь Сумарокова вряд ли возможно обнаружить. Традиционно для переложения псалмов использовался тип ababcc, что видно, к примеру, у Ломоносова («Вечернее размышление о Божьем величии...»). Надо сказать, что в своих переводах Сумароков не столь часто прибегает к такому типу рифммовки, что отличает его от более последовательного Ломоносова.

Всего в данном стихотворении три строфы, каждая из которых при помощи обозначенной рифмовки дробится на две симметричные друг другу части: 3 первых и 3 последних. Раздел между ними обозначается Сумароковым соответствующим знаком препинания: либо точкой, либо точкой с запятой. Можно проследить и разделение смысловой нагрузки между двумя частями строфы: в первой из них дается тезис, во втором - его развертывание. Своеобразие организации строф избранного стихотворения заключается в следующем. В отличие от, казалось бы, дублирующего стих 6 стиха 3 первой строфы, размер 6-го равен не Я6, а Я4, как в 4 и 5, что производит, условно говоря, «эфффект двойного нарушения ожидания» и выделяет вто- рую часть данной строфы на фоне первой. Иначе говоря, общий ритмический строй строфы стихотворения выглядит как Я446446; но если стих 3 нарушает ожидание читателя, который после стихов 1 и 2 ожидает увидеть вновь Я4, то стих 6 также нарушает читательское ожидание, потому как читатель, помня о стихе 3, ожидает в симметричном ему стихе вновь увидеть Я6. В большей степени оригинально то, что отмеченная ситуация не повторяется в строфрах 2 и 3. Подобные случаи нетождественности строф по отношению друг к другу в пределах одного стихотворения были подробно рассмотрены К.Д. Вишневским в статье «Нетождественные строфы в русской поэзии XVIII-XIX вв.: Классификация и функции». Апеллируя к данной работе, можно отнести встретившуюся в избранном тексте строфру к типу 5 (случай, когда строфы различаются стопностью) [12, с. 53]. Следуя за ученым, охарактеризуем строфы стихотворения Сумарокова следующим образом: ааВссВ Я446444 - строфра 1; ааВссВ Я446446 - строфы 2 и 3. Исследователь также замечает, что для всего корпуса поэтических текстов Сумарокова количество стихотворений с нетождественными строфрами (HC) равно 40 [13, с. 53], поэтому в контексте творчества данного поэта это явление нельзя назвать чем-то из ряда вон выходящим.

Характеризуя мелодику стихотворения, надо в целом заметить, что данный текст можно назвать разговорным ораторским. Прежде всего, обращает на себя внимание сама тема стихотворения, контрастирующая с напевным стихом - философское рассуждение о людских грехах и тленности мирских почестей. Стихотворение начинается почти ораторским, призывным обращением к читателям: «Не уповайте на князей». Помимо этого, сама лексика произведения стилистически относится к «высокому» церковнославянскому регистру: «уповать», «презреть», «помышлять», «гордость», церковнославянизм «кратки», упомянутая выше «библейская» словоформа «человеки» и т. д.

Нельзя, однако, отрицать наличия в данном тексте явных элементов напевного песенного стиха. Во-первых, он имеет в общем симметричную строфическую организацию; во-вторых, нередки в нем синтаксические параллелизмы, также создающие ощущение определенной симметрии; в-третьих, на протяжении всего стихотворения интонационное членение совпадает с метрическим, то есть пауз внутри одной стихотворной строчки не наблюдается; в-четвертых, не наблюдается и типичный для разговорного стиха перенос (enjambement). Характерным признаком песенного стиха является также усиление интонации и ее определенное противоречие смыслу текста, что демонстрирует стих 12: при первом прочтении «длинной» 6-стопной строчки и улавливании ее основного образа перед глазами читателя возникает образ широкой, величественной, неспешно текущей реки (подобный эффрект, вероятно, создается при помощи словораздела и 
интонации: ударение на первом слоге в слове «гордые» и дактилический словораздел создают ощущение, что строка, по выражению Г.А. Шенгели, звучит «ниспадающе и тягуче» [13, с. 163], что подчеркивает в стихотворении напевность и мелодичность), в то время как в действительности поэтом изображается бурная, шумная река, о чем свидетельствуют деепричастие «шумя» и наречие «быстро». Из сказанного следует, что в стихотворении усматривается и мелодическая симметрия - равномерное повышение и понижение голоса в пределах стиха, иначе говоря - каденция. Таким образом, смешение характерных черт напевного песенного и говорного ораторского стиха создают оригинальный синтез. Это вполне объяснимо, потому как данное произведение представляет собой переложение псалма, то есть текста, изначально ориентированного на пение - отсюда песенная интонация. Интонация же ораторская, очевидно, появляется в результате своеобразной «секуляризации» текста: непосредственному обращению к широкому читателю. (Возможно, благодаря этому в стихотворение вкрапляются нормы таких жанров, как, например, светский панегирик и т. п.) Помимо этого, как справедливо считает Н.А. Гуськов, насыщение перевода священного текста дополнительной разговорной интонацией обуславливается еще и стремлением поэта пробудить у читателей личный интерес к философским проблемам человеческого бытия [3, c. 34]. Дополнительно подчеркивает эту тему и интонационное выделение в стихе 3 ключевого слова - «естество» («И всяк по естеству на свете честью равен»): пропуск ударения в стихе на второй стопе создает восходящее движение голоса к ударению в ключевом слове стиха, что усиливается при помощи резкого мужского словораздела. Это подкрепляет фригурировавший ранее тезис о том, что главным для Сумарокова является мысль о природном, «естественном» равенстве людей, что сближает поэта с просветительскими тенденциями эпохи.

Еще одним аспектом мелодики избранного стихотворения, на который стоит обратить внимание, является микромелодика стихов 4-6 (строфа 1). Ритм, заданный в них Я4, подкрепляется словоразделом, в результате чего на протяжении одного стиха происходит повышение и понижение голоса в соответствии с числом иктов - четыре раза. Подобные голосовые колебания, резкая, отрывистая интонация, диктуемая размером, словно «уплотняют» текст, делают заключенную в нем сентенцию - о цикличности жизни и смерти человека вне зависимости от материального достатка и общественного положения - непререкаемой истиной, незыблемым фрактом.

Подводя итоги, сравним результаты анализа данного текста, полученные на разных уровнях, и охарактеризуем общую композицию стихотворения.

Общая композиция данного текста реализуется по следующей схеме: строфра 1 - задается основная мысль; строфы 2 и 3 - ее развертывание. Частые повторы наблюдаются в стихотворении на самых разных уровнях. На уровне фоники - звуком /э/ также задается тема, размывающаяся к концу строфы 2, практически сходящая на нет в начале строфы 3 и возобновляемая в конце. На уровне метрики и ритмики - ритмически строфра 1 также задает основной тон стихотворению, который, однако, нарушается неупорядоченным словоразделом в строфе 2 и более упорядочивается в строфе 3; пропуски метрических ударений наиболее упорядочены в начале строфы 1 (где в первых двух стихах создают ритмическую анафору), практически отсутствуют в ее конце и редки в строфе 3 , зато чаще всего встречаются в середине стихотворения - строфе 2 . Также своеобразная анафора создается - уже на лексическом уровне - в строфрах 2 и 3 при помощи употребления слов «тогда» и «когда», которые оба являются наречиями времени.

Можно сказать, что на этих двух уровнях реализуется следующая условная схема: задается тема - тема нарушается - происходит ее постепенное восстановление; иными словами, также реализуется кольцевой принцип. Подкрепляется данная мысль и сопоставлением текста Сумарокова с означенным первоисточником: почти дословно цитируя псалом 145 в начале стихотворения, поэт отказывается от него во второй строфре и заключает в середину текста свои собственные философскоэтические воззрения - выдвижение мирских грехов (лести и суеты) в качестве причины отсутствия духовного спасения, яркий образ реки жизни, переплетающийся с темой смерти; в заключительной же строфе 3 поэт снова обращается к цитированию первоисточника. Полученная в итоге схема - тема, нарушение, возвращение - поддерживается многими уровнями стихотворения и воплощает, судя по всему, мысль о бесконечном чередовании жизни и смерти, «круговороте» и замкнутом цикле человеческого бытия. Таким образом, можно проследить, как преобразуется под пером поэта традиционный жанр из священной христианской книги.

Отдельное внимание стоит уделить строфе 1. Необычность ее в том, что, как видится, в ней одной воплощены все элементы выделенной схемы. Ритм стихов 1 и 2 задает общий тон, стих 3 разрушает его, после чего он восстанавливается в стихах 4-6. На уровне семантики также наблюдается сходство: первые два стиха задают тему, после чего идет ее развертывание. Учитывая вышесказанное, можно прийти к выводу, что строфра 1 по структуре представляет собой как бы все стихотворение в миниатюре. Являясь внутри себя реализацией предложенной Сумароковым схемы, она, тем не менее, есть составной элемент структуры более высокого порядка - текста всего стихотворения. Другими словами, она словно существует в двух ипостасях: будучи прочитанная первой, она остается в памяти читателя как целостная структура, заключающая в себе упомянутую ранее схему: задается тема - от- 
ступление - возвращение; однако, вступая в отношение в другими строфрами исследуемого текста, она реализует себя как единый, более крупный элемент в рамках структуры стихотворения, сама являясь первым элементом в синтагматическом развертывании схемы. Две же оставшиеся строфы - номера 2 и 3 - семантически, как кажется на первый взгляд, являются тождественными, поскольку заключают в себе лишь вариации темы, заданной в строфре 1, но проведенный анализ показал, что они не только остаются в рамках парадигматики, но и реализуют себя на синтагматической оси текста данного стихотворения (используется терминология Р.Я. Якобсона [14, с. 193-230]). В результате возникают черты последовательного лирического сюжета: с точки зрения фоники - от упоминания смерти к ее изображению; с точки зрения ритмики текст приобретает кольцевую композицию.

\title{
ЛИТЕРАТУРА
}

1. Аверинцев С.С. София-Логос. Словарь. - Киев, 2006

2. Гуковский Г.А. Русская литература XVIII в. - М., 1998.

3. Гуськов Н.А. А.П. Сумароков. Духовная поэзия: учебное пособие по курсу «История русской литературы XVIII века». - СПб., 2009

4. Полный православный богословский энциклопедический словарь. - СПб.: Изд-во П.П. Сойкина, 1912.

5. Берков П.Н. Комментарий: Сумароков. Из 145 псалма // Сумароков А.П. Избранные произведения. - Л.: Советский писатель, 1957.

6. Сумароков А.П. Стихотворения. - Л.: Советский писатель, 1935.

7. Библия, сиречь книги Священного Писания Ветхого и Нового Завета. - СПб., 1751. Т. 2.
8. Луцевич Л.Ф. Псалтырь в русской поэзии. - СПб., 2002.

9. Брик О.М. Звуковые повторы // Поэтика: Сборник по теории поэтического языка. - Пе., 1919.

10. Вишневский К.Д. Русская метрика XVIII века // Вопросы питературы XVIII века. - Пенза, 1972.

11. Словарь Академии Российской. Ч. 2. - СПб.: Изд-во при Императорской Академии Наук, 1790.

12. Вишневский К.Д. Нетождественные строфы в русской поэзии XVIII - XIX в8.: Классификация и фрункции // Онтология стиха: Сборник статей памяти Владислава Евгеньевича Холшевникова. - СПб., 2000.

13. Шенгели Г.А. Техника стиха. - М., 1960.

14. Якобсон Р.О. Лингвистика и поэтика // Структурализм: «за» и «против». - М., 1975.

\section{THE EXPERIENCE OF THE INTEGRATED LINGUISTIC ANALYSIS OF A.P. SUMAROKOV'S POEM «ROM PSALM 145» (1773)}

\author{
A.Y. Trofimov
}

student, St. Petersburg State University, Faculty of Philology (artem_trofimov_9@mail.ru).

\begin{abstract}
The article provides a comprehensive linguistic study of A.P. Sumarokov's poem "From Psalm 145"; the genre specificity of the text, peculiarities of its style, phonics, metrics, strophic, lexis, composition are being revealed, as well as the elements of poetic innovation and the degree of its correspondence to classicistic canons.
\end{abstract}

Keywords: A.P. Sumarokov, classicism, Psalm, strophe, verse, style, language, translation.

\section{REFERENCES}

1. Averintsev S.S. Sofiya-Logos. Slovar'. - Kiev, 2006.

2. Gukovskiy G.A. Russkaya literatura XVIII v. - M., 1998.

3. Gus'kov N.A. A.P. Sumarokov. Dukhovnaya poeziya: uchebnoe posobie po kursu "Istoriya russkoy literatury XVIII veka». - SPb., 2009.

4. Polnyy pravoslavnyy bogoslovskiy entsiklopedicheskiy slovar'. - SPb.: Izd-vo P.P. Soykina, 1912.

5. Berkov P.N. Kommentariy: Sumarokov. Iz 145 psalma // Sumarokov A.P. Izbrannye proizvedeniya. - L.: Sovetskiy pisatel', 1957.

6. Sumarokov A.P. Stikhotvoreniya. - L.: Sovetskiy pisatel', 1935.

7. Bibliya, sirech' knigi Svyashchennogo Pisaniya Vetkhogo i Novogo Zaveta. - SPb., 1751. T. 2.

8. Lutsevich L.F. Psaltyr' v russkoy poezii. - SPb., 2002.

9. Brik O.M. Zvukovye povtory // Poetika: Sbornik po teorii poeticheskogo yazyka. - Pg., 1919.

10. Vishnevskiy K.D. Russkaya metrika XVIII veka // Voprosy literatury XVIII veka. Penza, 1972.

11. Slovar' Akademii Rossiyskoy. Ch. 2. - SPb.: Izd-vo pri Imperatorskoy Akademii Nauk, 1790.

12. Vishnevskiy K.D. Netozhdestvennye strofy $v$ russkoy poezii XVIII - XIX vV.: Klassifikatsiya i funktsii // Ontologiya stikha: Sbornik statey pamyati Vladislava Evgen'yevicha Kholshevnikova. - SPb., 2000.

13. Shengeli G.A. Tekhnika stikha. - M., 1960.

14. Yakobson R. O. Lingvistika i poetika // Strukturalizm: «za» $i$ «protiv». - M., 1975. 